International Journal of Linguistics, Literature and Translation (IJLLT)

ISSN: 2617-0299 (Online); ISSN: 2708-0099 (Print)

DOI: $10.32996 / \mathrm{jjllt}$

Journal Homepage: www.al-kindipublisher.com/index.php/ijllt

IJLLT

\title{
Personal Value Typology in the Moroccan Context: An examination of High School Students' Orientations in Light of Gender and Ecology
}

Sanae Mamnoun ${ }^{1 *}$, Abdelhamid Nfissi ${ }^{2} \&$ Ben Ahmed Hougua ${ }^{3}$

${ }^{1}$ Ph.D. Candidate, Faculty of Arts and Human Sciences, Sais fez, Sidi Mohamed Ben Abdellah, Morocco

${ }^{2}$ Senior Professor, Faculty of Arts and Human Sciences, Sais Fez, Sidi Mohamed Ben Abdellah. Morocco

${ }^{3}$ Professor Researcher of Political Science, Faculty of Law, Economics and Social Sciences, Sidi Mohamed Ben Abdellah.

Morocco

Corresponding Author: Sanae Mamnoun, E-mail: sanae.morina@yahoo.com

\section{ARTICLE INFORMATION ABSTRACT}

Received: November 08, 2020

Accepted: December 17, 2020

Volume: 3

Issue: 12

DOI: 10.32996/ijltt.2020.3.12.24

\section{KEYWORDS}

Instrumental values, terminal values, social goals, personal goals, gender, ecologies
This study sought to examine the personal value types of high school students in Fez and its suburbs. It used a sample of 376 subjects and employed the Rokeach's (1973) value survey instrument and the Musser and Orke (1992) typology to classify the personal values into types. The authors tested for differences by gender and geographical area. Findings revealed no gender differences in value type preferences since both male and female students were more alike than different in their value orientation by falling into the category of the Independent Maximizer. However, significant differences were noticed regarding the geographical area to which the respondents belong. Accordingly, the dominant value type of the sample was that of the Independent Maximizer represented by the students of Fez, followed by the Honorable Egoist exemplified by the students of Sefrou. The least frequent types were the Effective Crusader and the Virtuous Advocate under which the students of Tawjdate were classified. The authors discussed the findings with respect to anthropological and historical framework.

\section{Introduction}

Each individual holds specific values that influence the way he or she thinks, believes, acts, and reacts. Concepts such as freedom, safety, independence, kindness, and others may seem to have varying degrees of importance according to what individuals believe to be principles or standards they take into consideration in dealing with different aspects of their daily lives. This implies that a specific value may be very significant to one person, but it may be on the other hand less important to another depending on the motives and goals that urge people to maintain particular values at the expense of others. Indeed, there has always been an agreement among theorists that values are universal; however, there exists a wide variation regarding the order of importance to how values are organised. In this sense, people everywhere have essentially the same values but the priorities given to specific values may differ across individuals, groups and cultures (Kluckholm, 1951; Rokeach, 1973; Schwartz, 1992, 2012; andWilliams, 1968).

Additionally, values can be either positive or negative. Positive values have always established progress, peace and boosted humanitarianism, whereas negative values have caused wars, persecution and inhuman acts (Hultman, 2017). Thus, the light and dark aspect of values has encouraged philosophers, since ancient Greece to address and embrace values in their writings. From what has been stated so far, one can infer that values cannot be static but rather dynamic variables because some may increase or decrease in importance, others may fade away over time as individuals gain in knowledge and experience (ibid).

Apparently, many formal definitions of values exist in the literature, but there are basically five common features that provide a comprehensive conceptualization of values that can be summarized, according to Smith and Schwartz (1997) as follows:

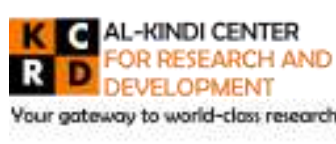

Published by Al-KindiCenter for Research and Development. Copyright (c) the author(s). This is an open access article under CC BY license (https://creativecommons.org/licenses/by/4.0/) 
a. Values are beliefs and concepts which are associated with emotions. Once individuals enjoy a specific value, they feel happy and satisfied, but once that value is threatened or not protected, they can be helpless.

b. Values are desirable goals people strive to achieve.

c. Values transcend specific actions and situations. That is, they are abstract goals; a feature which distinguishes values from concepts such as norms and attitudes which basically refer to actions, objects or situations.

d. Values serve as standards, norms or criteria that guide the selection and evaluation of our behaviour.

e. Values are ordered by relative importance. This hierarchical nature of values also differentiates them from norms and standards.

\section{The Literature Review}

In his famous book "The Nature of Human Values" Rokeach (1973) developed his own definition of values describing them as "an enduring belief that as a specific mode of conduct or end-state of existence is personally or socially preferable to an opposite or converse mode of conduct or end state of existence" (p. 5). Actually, two sets of values can be inferred from the above definition; those which are final states of existence and values which are specific modes of behaviour. The former set is called terminal values reflecting the goals a person aims to reach throughout his or her lifetime and may vary among different groups of people and among different cultures. Concepts such as freedom, equality, pleasure and happiness are examples of Rokeach's terminal values. As for the latter set of values, they are labelled instrumental since they serve as means or preferable modes of behaviour to achieve the desirable objectives or terminal values. They comprise personal characteristics and character traits including being ambitious, responsible and independent.

Rokeach (1973) further subdivided both terminal and instrumental values into two subcategories each. In this respect, terminal values may be personal (self-oriented and intrapersonal) or may be social (society-oriented and interpersonal). Instrumental values on the other hand may be classified into moral with an interpersonal focus (other-oriented) and competence with a personal focus (self-oriented). According to Musser and Orke (1992), a violation of moral instrumental values leads to a feeling of guilt for wrong doing whereas a violation of competence instrumental values may result in a feeling of shame about personal inadequacy. What seems to be important in Rokeach's hierarchical theory is not having that specific value or the other, but how high the given value is ranked in a person's value hierarchy. In other words, the higher the value is, the most crucial and influential will be in shaping beliefs, attitudes and behaviour. The following table provides a list of Rokeach's values:

Table 1: A Listing of Rokeach's Value Types

\begin{tabular}{ll}
\hline Social terminal values (focus on others) & Personal terminal values (focus on self) \\
A World at Peace & A Comfortable Life \\
A World of Beauty & An Exciting Life \\
Equality & A Sense of Accomplishment \\
Family Security & Happiness \\
Freedom & Inner Harmony \\
Mature Love & Pleasure \\
National Security & Salvation \\
Social Recognition & Self-respect \\
True Friendship & Wisdom \\
& \\
Moral instrumental values (focus on others and morality) & Competence instrumental values (focus on self and \\
Broadminded & competence) \\
Forgiving & Ambitious \\
Helpful & Capable \\
Honest & Clean \\
Loving & Courageous \\
Cheerful & Imaginative \\
Obedient & Independent \\
Polite & Intellectual \\
Responsible & Logical \\
& Self-Controlled \\
\hline
\end{tabular}

Source: adapted from Rokeach (1973) and Musser and Orke (1992) 
Rokeach's (1973) classification of values is still a basis for several modern studies although his theory has been developed for more than forty years (Tuulik et al., 2016).Many theorists have emphasised the importance of studying values to understand social behaviour. (e.g., Allport, Vernon, and Lindzey, 1960;Kluckhohn, 1951;Rokeach, 1973; Williams, 1968). They consider values as abstract motivations that justify and guide beliefs, attitudes, and opinions that influence the way we act in different situations (see also Feather, 1985;Rokeach, 1973; Schwartz, 1992). Values may also be considered, according to Gellerman, Frankel,andLadenson (1990), as standards or criteria upon which individuals can make choices and decisions, establish goals, and set priorities.

\subsection{Musser and Orke (1992) typology}

Musser and Orke (1992) developed a typology of ethical behaviour based on placing Rokeach's value types onto a matrix. In this respect, the two researchers combined two types of terminal values and two types of instrumental values onto a two by two matrix which generates a typology containing four different basic value system types that people behave accordingly as follows:

a. The Virtuous Advocates are more concerned about helping others rather than focusing on achieving their personal goals. Such people are sensitive to others, caring and other centered (Arial, Abdolmohammadi, and Murphy Smith, 2015). They also employ moral means rather than competence means to reach social goals. Musser and Orke found that Mother Teresa and Mahatma Ghandi would likely to fit into this classification of value system typology.

b. The Effective Crusaders hold more concern for the other rather than for the self. They prioritize the goals of others over their personal goals. They employ competence means rather than social means to attain social goals. People within this category score high on competence instrumental values and social terminal values (Giacomino and Eaton, 2003). The Musser and Orke study classified Oliver North in the Effective Crusader value system.

c. The Independent Maximizers are more focused on themselves as opposed to others. They are insensitive to the needs and feelings of others to reach their personal goals and interests. Individuals who fall into this category score higher on personal terminal values and competence instrumental values. Independent maximaziers are often viewed with a great deal of narcissism, machiavellianism and mistrust. Donald Trump and Ivan Boesky have a value system consistent with independent maximizers according to Musser and Orke validation study.

d. The Honorable Egoists are insensitive to the needs and feelings of others, they seek to achieve their personal ends and objectives through moral means rather than competence means. Honourable Egoists are viewed with suspicious because of their self-interest objectives (Giacomino, Li and Akers, 2013). Arsenio Hall is an example of honourable egoist in line with Musser and Orke value system classification study.The following table illustrates well the four different value type systems as advocated by Musser and Orke (1992):

Table 2: The Value System Matrix

\begin{tabular}{|c|c|c|c|}
\hline \multirow{4}{*}{ 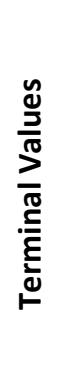 } & & \multicolumn{2}{|c|}{ Instrumental Values } \\
\hline & & High Competence & High Moral \\
\hline & $\begin{array}{l}\text { High } \\
\text { Social }\end{array}$ & $\begin{aligned} \text { Effective } & \text { Crusader (EC) } \\
- & \text { Concern for others } \\
- & \text { Competence means for social goals }\end{aligned}$ & $\begin{aligned} \text { Virtuous Advocate (VA) } \\
-\quad \text { Concern for others } \\
-\quad \text { Moral means for social goals }\end{aligned}$ \\
\hline & $\begin{array}{l}\text { High } \\
\text { Personal }\end{array}$ & $\begin{array}{l}\text { Independent Maximizer(IM) } \\
-\quad \text { Concern for self } \\
-\quad \text { Competence means for personal } \\
\text { goals }\end{array}$ & $\begin{array}{l}\text { Honorable Egoist (HE) } \\
\begin{aligned}- & \text { Concern for self } \\
- & \text { Moral means for personal } \\
& \text { goals }\end{aligned} \\
\end{array}$ \\
\hline
\end{tabular}

Source: Adapted from Musser and Orke (1992), and Eaton and Giacomino (2001)

\subsection{Gender and Value type preferences}

Prior research on gender differences has focused on ethical differences, rather than personal value preferences (Eaton \& Giacomino, 2001). Various results have been found in this area. Some research studies suggested that females were more ethical than men, other studies, however, found little or no gender differences on ethical perceptions and beliefs (ibid). A little amount of research, however, has investigated the value types based on Musser and Orke (1992) typology and the variable of gender. Very few studies have found both male and female respondents having the same value type. For instance, Giacomino, Fujita, and Johnson (1999) found that both genders of Japanese business managers were predominantly Honorable Egoists. Other studies found that the variable of gender was highly significant. Accordingly, the Independent Maximizer category was the dominant value type for male subjects (e.g.Arial, et al., 2012; Eaton \& Giacomino, 2000; 2001; and Giacomino\& Eaton, 2003), whereas females were classified as either Virtuous Advocates or Honorable Egoists. For instance, Eaton and Gicomino (2000) applied the Musser and Orke methodology to business students and found that females 
were more likely to be Virtuous advocates. Similarly, in another study, both researchers (2001) found that the most frequent value system type for female accounting students was that of the Virtuous Advocate. Notice that in both studies, male subjects were described as Independent Maximizers with a personal focus rather than a social focus.

The same results were echoed in Giacomino and Eaton's (2003) study of accounting practitioners with the Virtuous Advocate being the most frequent value type among females while the Independent Maximizer was the dominant type for the male group. The interpretation of this can be justified by the females' caring nature and their tendency to serve the other through moral means which urge them to be more social-oriented. On the other hand, males were described as being more focused on self because of their tendency to use competence instrumental means to serve their personal terminal objectives. This fact accounts for the widespread presence of the Independent Maximzer profile among male subjects.

Nevertheless, other studies reported that females were mainly classified as Honorale Egoists. One example of this classification is the study of Arial et al., 2012 in which 304 Certified Public Accountants were surveyed to determine value type preferences. The overall results concluded that male subjects exhibited preference for personal and competence values compatible with the Independent Maximizer value type while females demonstrated preference for personal terminal values and moral instrumental values that correspond to the Honorable Egoist value type. In other words, both genders have the same self-centered terminal goals but the means for achieving those goals differ in the sense that males employ competence means to get personal gain, whereas females tend to focus more on moral means to attain personal objectives.

In a Chinese context, however, Giacomino, Li, and Akers (2013) have found that male business students were more social oriented than females since the Effective Crusader and the Virtuous Advocate were classified as the most dominant categories among the male respondents, while the female students were described as being more self-centered since they were described as Effective Crusaders and Independent Maximizers respectively. That it so say, males used competence and morality to reach social ends. Females, on the other hand, seemed to place an emphasis on self-oriented ends. The researchers attributed the shift towards a self-focused value orientation among Chinese female respondents to the change in women's social status in china as they have gained more social rights that enabled them to enter the job market and change their traditional gender role (ibid).

In general, most studies that have investigated the value type preferences based on Musser and Orke (1992) typology and gender as an independent variable confirmed that males were more classified as Independent Maximizersdue to their selffocused nature and their tendency to rely on competence to serve their personal goals. On the contrary, females were more described as Virtuous Advocates or Effective Crusadersas they show more concern towards serving others as terminal values and ends. Few studies endorsed no gender differences as far asvalue type preferences are concerned.

The research question for this given study will be presented as:

- What are the most prevailing value systems among Moroccan high school students? And how may these value typologies vary with respect to gender and ecology?

\section{Methodology}

The current study used the Rokeach Value Survey (Rokeach, 1973) to identify value preferences and the Musser and Orke (1992) typology to determine value type preferences or systems. To reach this end, subjects were asked to complete the survey by ranging 18 terminal values followed by 18 instrumental values in terms of their degree of importance to them. The results of the survey were used to find out subjects' value system types by applying the Musser and Orke (1992) methodology.

The sample chosen randomly according to the administrative authorization provided is composed of 376 high school students (165 males and 210 females) belonging to different public institutions in Fez and its suburbs, including Taoujdate, Sefrou and Ain Cheguag.The students were invited to complete the Rokeach Value Survey during class. It was administered in Arabic to guarantee the comprehension of the different items and concepts of question content and eliminate any area prone to ambiguity or misinterpretation. To elicit demographic information such as age, gender, level, subject, etc., a section was included to achieve this goal. The respondents were assured that confidentiality and anonymity would be maintained and stressed. The following table shows the sample distribution by institutions enrolled in four ecologies differently located according to the urbanization index: 
Table 3: The Institution Ecologies of the Study

\begin{tabular}{|c|c|c|c|c|c|c|}
\hline & \multicolumn{4}{|c|}{ Ecologies of the study } & \multirow[b]{2}{*}{ Total } \\
\hline & & $\begin{array}{l}\text { Ain } \\
\text { Chgag }\end{array}$ & Fez & Sefrou & Taoujtat & \\
\hline \multirow[t]{8}{*}{ Institution } & 11Janvier & & & & $14,6 \%$ & $14,6 \%$ \\
\hline & $\begin{array}{l}\text { Abi Salim } \\
\text { Laayachi }\end{array}$ & $4,0 \%$ & & & & $4,0 \%$ \\
\hline & Allal Elfassi & & $12,5 \%$ & & & $12,5 \%$ \\
\hline & Ibn Hazm & & $49,8 \%$ & & & $49,8 \%$ \\
\hline & Ibn Souda & & $4,0 \%$ & & & $4,0 \%$ \\
\hline & LahssenLyoussi & & & $10,4 \%$ & & $10,4 \%$ \\
\hline & Moulay Idriss & & $4,8 \%$ & & & $4,8 \%$ \\
\hline & & $4,0 \%$ & $71,1 \%$ & $10,4 \%$ & $14,6 \%$ & $100,0 \%$ \\
\hline
\end{tabular}

In order to get the scores of the subjects on social or personal terminal values as well as the moral and instrumental values, we subtracted the total rankings of each group from 171 (the sum of rankings for all values in the set). The following syntax illustrates the operations that were followed:

\section{Figure 1: Syntax}

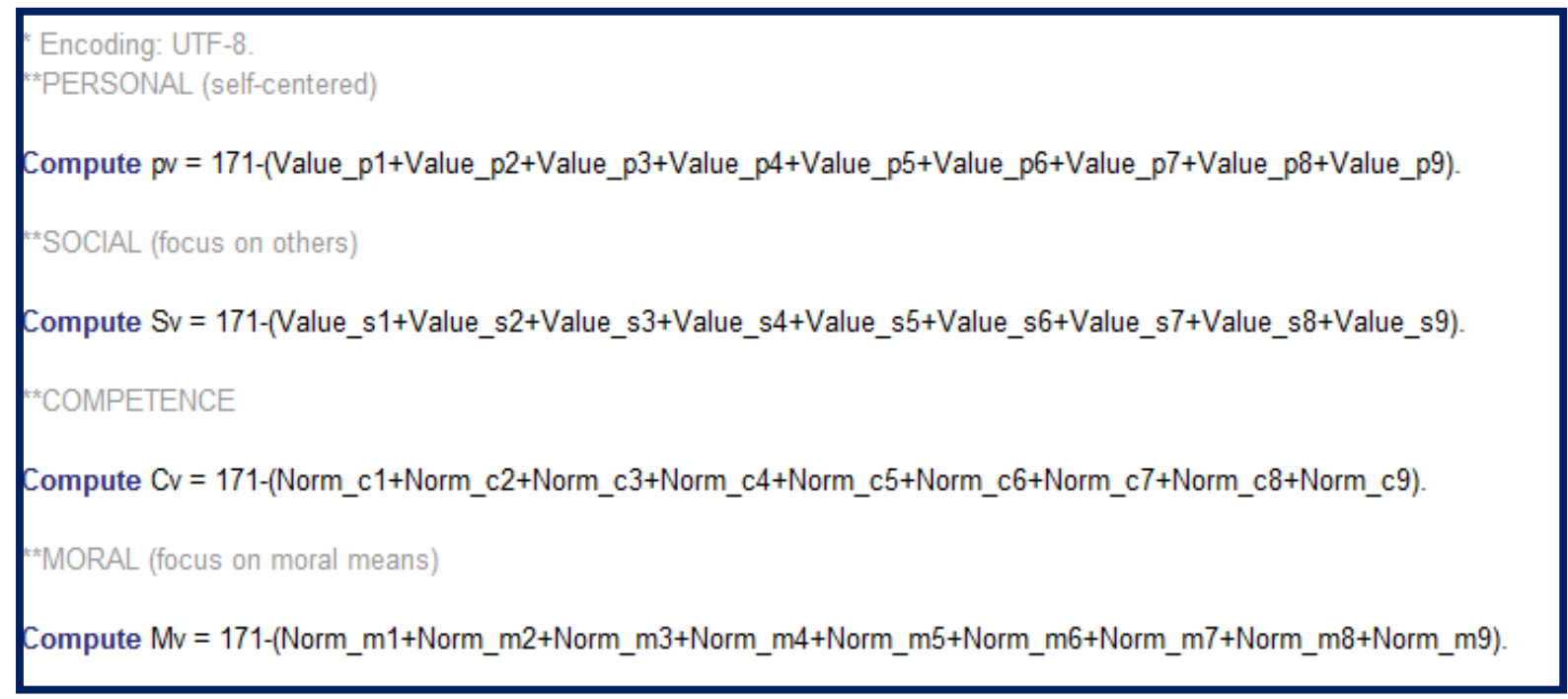

Only terminal and social values count in the construction of the cultural typology according to Musser and Orke (1992). Thus, the high scores on social values indicate a social orientation while the lower scores show personal and selfish orientation. This also applies to moral values in which lower average scores reflect the endorsement of competence preferences, while high scores tend to focus on moral orientation.

Both researchers are content with the average of the two set of values to separate the weak and strong scores. However, this technique seems likely to generate hybrid and mixed categories. To avoid such a metric risk, the scores indicating the personal values and those related to the option for the competence were subtracted from the mean deviation (standard deviation). Scores of moral and social orientations are obtained by adding the standard deviation to the mean (mean + standard deviation). This method makes it possible to refine the analysis by eliminating the cases demonstrating a cultural make-up making them difficult to be classified in a given category. The table below illustrates the combination to the principle of the typology adopted: 
Table 4: the combination of value types

\begin{tabular}{|l|l|l|l|}
\hline & & \multicolumn{2}{|c|}{ Social Terminal Values } \\
\hline & & low & high \\
\hline \multirow{2}{*}{$\begin{array}{c}\text { Moral Instrumental } \\
\text { Values }\end{array}$} & low & Independent Maximizer & Effective Cruzader \\
\cline { 2 - 4 } & high & Honourable Egoists & Virtuous Advocate \\
\hline
\end{tabular}

\section{Results and Analysis}

The descriptive analysis of the profiles, which constitutes the cultural typology adopted by the researchers, shows significant proportions. The graph below demonstrates the weight of each profile in the sample studied:

Figure 2: Cultural profiles of all respondents

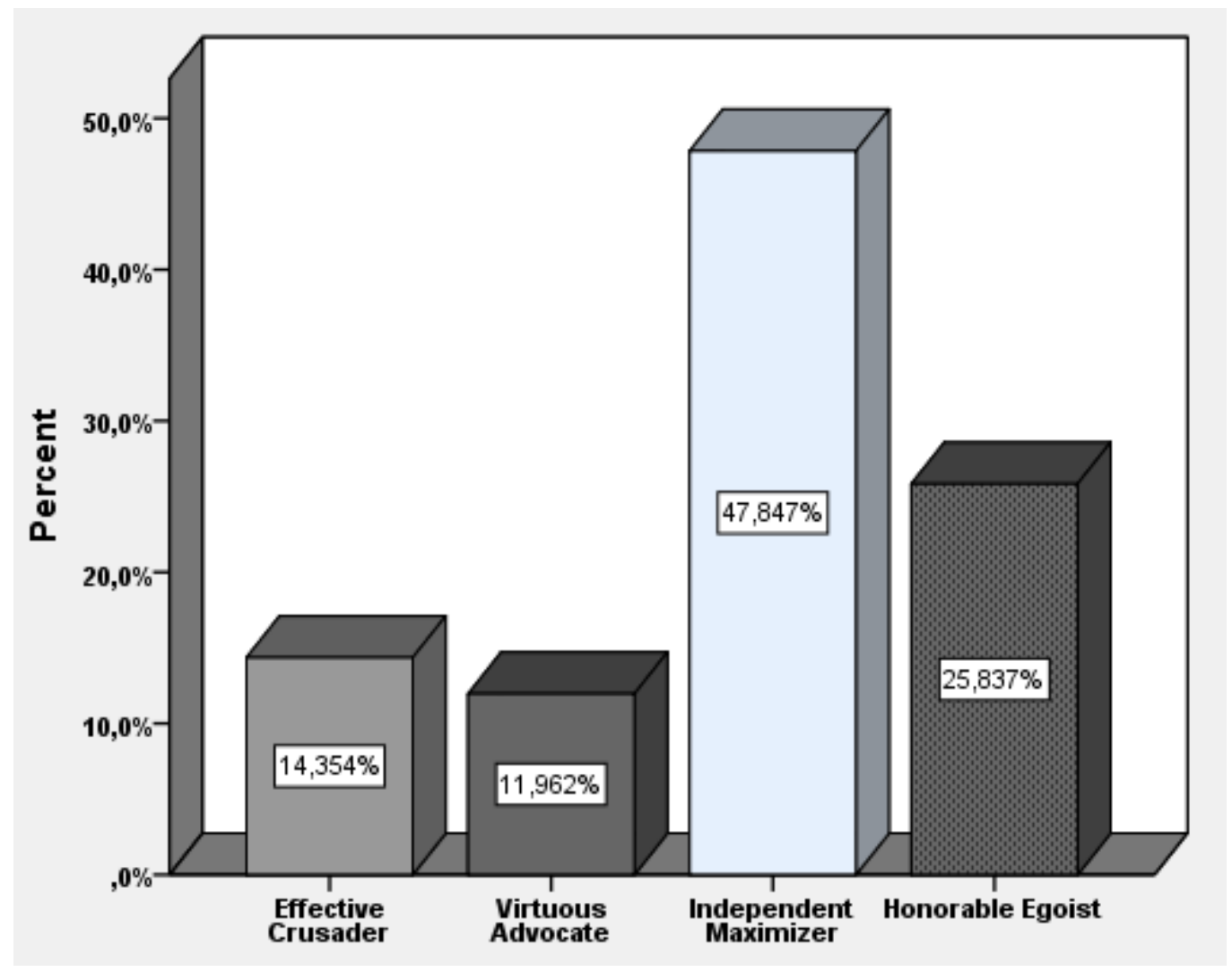

It is undoubtedly obvious from the above diagram that the dominant $(47,847 \%)$ value system for the sample is the Independent Maximizer. Subjects under this classification scored high on competence instrumental values and personal terminal values.A categorization which is, theoretically, associated with Machiavellianism, narcissism and mistrust since it is based on the use of competence means to achieve personal interests. The second most frequent value system $(25,837 \%)$ is the Honorable Egoist. Students with this value system identification scored high on moral instrumental values and personal terminal values. Thus is, it is a value system which makes use of morality to reach personal gain and end. Due to its personal focused nature, the Honorable Egoist should be regarded with mistrust and suspicion. Surprisingly, the Effective Crusader and the Virtuous Advocate came at the bottom of the sample value type classificationwith a percentage of $(14,35 \%)$ and $(11$, $96 \%)$ respectively. They are both social- oriented as a terminal value with a difference in the means used to achieve this end. In this context, the Effective Crusader employs competence as an instrumental value while the Virtuous Advocate relies on morality. The results of the given study are somehow consistent with Eaton and Giacomino (2001) findings in terms of the domination of the Independent Maximizer value type among American accounting students and managers. 
In terms of gender, the averages for boys and girls for each set of values are shown in the following table:

Table 3: Personal Values by Gender

\begin{tabular}{|c|c|c|c|c|}
\hline $\begin{array}{r}\text { Values } \\
\text { Averages }\end{array}$ & $\begin{array}{l}\text { Social terminal } \\
\text { orientation }\end{array}$ & $\begin{array}{l}\text { Personal terminal } \\
\text { orientation }\end{array}$ & $\begin{array}{l}\text { Moral instrumental } \\
\text { orientation }\end{array}$ & $\begin{array}{l}\text { Competence } \\
\text { instrumental } \\
\text { orientation }\end{array}$ \\
\hline Overall average & 79.83 & 91.17 & 82.64 & 88.73 \\
\hline Average among boys & 81.91 & 89.09 & 81.79 & 89.56 \\
\hline Average among girls & 78.37 & 92.63 & 83.24 & 88.15 \\
\hline T-test & $2.32 ;$ p 0.001 & $2.32 ; p<0.001$ & No sig & No sig \\
\hline
\end{tabular}

The t-test demonstrates that the differences between male and female students are rather significant as far as social values are concerned. Accordingly, male students exhibit a tendency to focus on social terminal values, whereas female students are more personal oriented. As for instrumental values, both genders are more alike than different in the means they employ to reach their ultimate goals.

The combination of the above value types contributes to the construction of the target profiles. The table below illustrates the classification of the students into four quadrants:

Table 4 :Gender Crosstabulation * Value System Matrix

\begin{tabular}{|c|c|c|c|c|c|c|c|}
\hline & \multicolumn{4}{|c|}{ Value System Matrix } & \multirow[t]{2}{*}{ Total } \\
\hline & & & $\begin{array}{l}\text { Effective } \\
\text { Crusader }\end{array}$ & $\begin{array}{c}\text { VirtuousAdv } \\
\text { ocate }\end{array}$ & $\begin{array}{c}\text { Independent } \\
\text { Maximizer }\end{array}$ & $\begin{array}{c}\text { Honorable } \\
\text { Egoist }\end{array}$ & \\
\hline \multirow[t]{4}{*}{ Gender } & \multirow[t]{2}{*}{ Male } & $\begin{array}{l}\text { \% within } \\
\text { gender }\end{array}$ & $20,9 \%$ & $11,6 \%$ & $47,7 \%$ & $19,8 \%$ & $100,0 \%$ \\
\hline & & $\%$ of total & $8,6 \%$ & $4,8 \%$ & $19,6 \%$ & $8,1 \%$ & $41,1 \%$ \\
\hline & \multirow[t]{2}{*}{ Female } & $\begin{array}{l}\text { \% within } \\
\text { gender }\end{array}$ & $9,8 \%$ & $12,2 \%$ & $48,0 \%$ & $30,1 \%$ & $100,0 \%$ \\
\hline & & $\%$ of total & $5,7 \%$ & $7,2 \%$ & $28,2 \%$ & $17,7 \%$ & $58,9 \%$ \\
\hline \multirow{2}{*}{\multicolumn{2}{|c|}{ Total }} & $\begin{array}{l}\text { \% within } \\
\text { gender }\end{array}$ & $14,4 \%$ & $12,0 \%$ & $47,8 \%$ & $25,8 \%$ & $100,0 \%$ \\
\hline & & $\%$ of total & $14,4 \%$ & $12,0 \%$ & $47,8 \%$ & $25,8 \%$ & $100,0 \%$ \\
\hline
\end{tabular}

Apparently, the most frequent value type of both male and female subjects is that of the independent Maximizer. That is, males and females alike place emphasis on serving themeslves rather than on serving others as they tend to employ competence instrumental means to reach personal terminal goals. These results, however, do not support findings of most previous research studies that classified women in the category of the Virtuous Advocate while men fit the Independent Maximizer profile. This might be attributed to the change of women's social position in the Moroccan society and to the country's 2011 constitutional reforms that enabled women to have more access to the public sphere and to gain more social and economic rights. Thus, women nomore adopt the traditional gender roles that used to confine them within the household responsilities of caring and serving their families. The second most frequent value orientation among female respondents is the Honourable Egoist (30,1\%) followed respectively by the Virtuous Advocate (12,2\%) and the Effective Crusader (9,8\%). Given that the most dominant value system $(47,7 \%)$ among male respondents is the Independent Maximizer, which corroborates with results of most previous studies, the Virtuous Advocate (11, 6\%) is classified at the bottom of male students' value sytem. The results for to the two remaining value typologies, the effective Crusader and the Honorable Egoist are balanced (20\% and $19,8 \%$ respectively) for male subjects.

Consequently, our study confirms that the differences between male and female students in the typology adopted are not significant as evidend by the value of chi-square (Chi square $=6,50, P>0,05$ ).

This study also seeks to examine the effect of the geograohical area or ecology on the students' value typology. The following graph demonstrates differences of students' value systems in terms of four different ecologies: 
Figure 3. Value System Marix by Ecologies

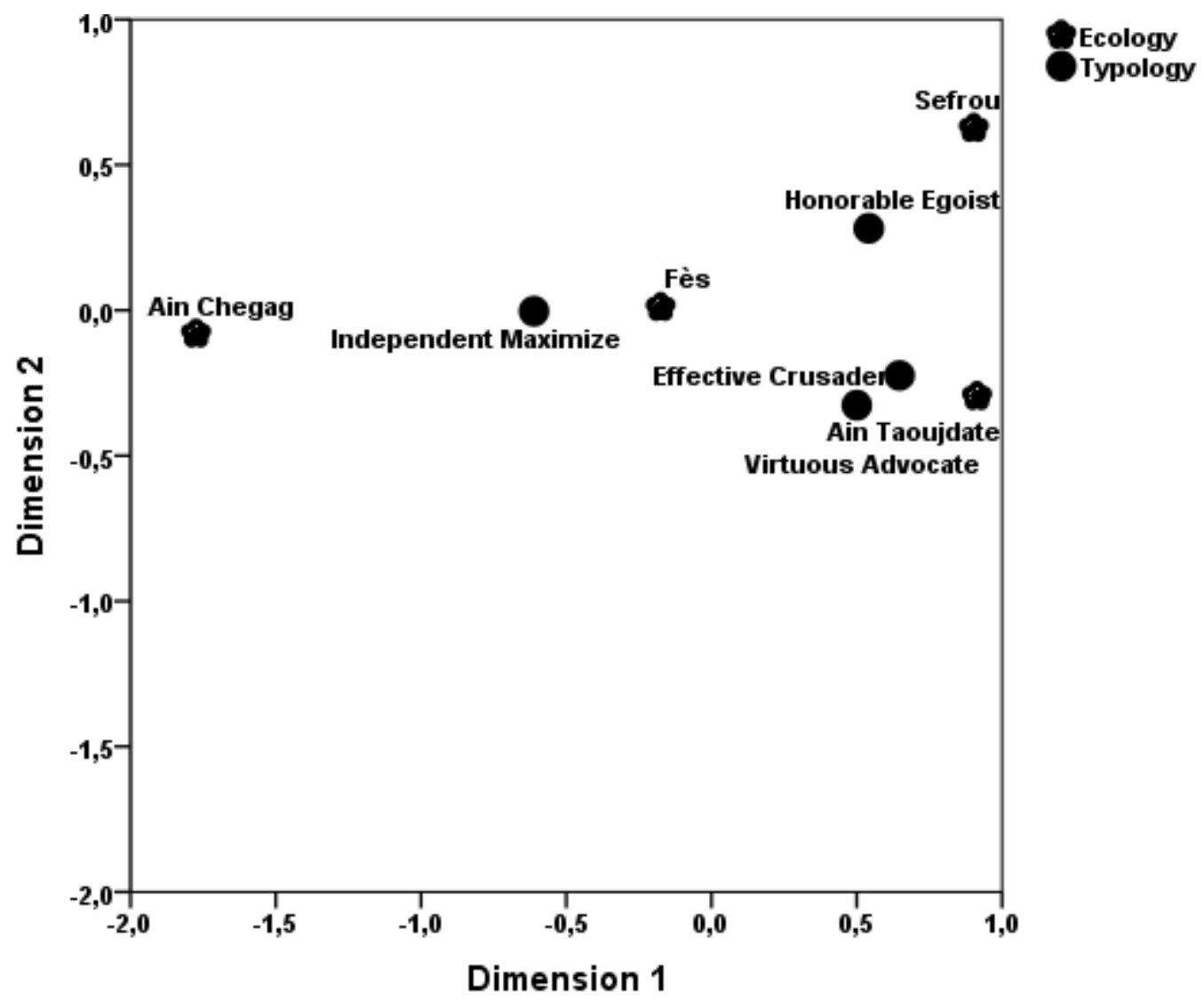

From the above diagram, one can notice that the students of Fez are classified according to Musser and Orke typology in the category of the Independent Maximizers. That is, they are described as individuals who employ their competence as an instrumental value to reach their personal interests as a terminal goal or value. The interpretation of these results can be attributed to the socialization process which influences the personal and cultural values and principles through which individuals perceive and effectively act in their social environment. According to Hougua (2018), the family is considered as the most important social institutional factor that generates people who are uncomfortable with the common good. He addressed the concept of "amoral familism", as advocated by the American political scientist Edward C. Banfield (1958), which describes an ego-centric family that cares only for its members' interests over the common good of the public as a selfinterested family centric society, the fact that accounts for its backwardness and underdevelopment (Hougua, 2019). On a theoretical basis, the cultural and moral orientation of individuals in Morocco fall into this construct of amoral familism through which subjects justify their defensive strategies towards the other. Additionally, Hougua (2018), in his unpublished thesis, has linked the vertical collectivist, as the most predominant social orientation group in Morocco, with the amoral familist in the sense that both are indifferent to the common good. In line with these results, the Independent Maximizer seems to share the same principles and motives that the vertical collectivist and the amoral familist uphold to achieve their own interests without paying attention to the other.

Evidence on the negative correlation between familism and the common good that results in the development of the Independent Maximizer value system in the Fassi culture was implicitly portrayed, from a historical point of view, by the French novelist Pierre Lotti (1890) who described the miserable conditions of the alleys of fez, while magnificent palaces and Riyades are hidden behind. In addition, Driss Chraibi (1954), in his famous book entitled Le Passé Simple, has also commented on the tenacity of the Bourgeois family structures, especially in the city of Fes.Moreover, John Waterbury (1970) is one of the researchers who talked about the social and political implications of familism in the Moroccan society. He pointed out, in his book the commander of the faithful, to the inability of the Moroccan subjects to move from the private sphere of the family circle to the public sphere of the community due to the collectivist or familist nature of the Moroccan culture. Thus, the family, as the most influential social institution, has always socialized its subjects to adopt the characteristics and principles of 
the vertical collectivist that correspond to those found in the Independent Maximizer category of Musser and Orke(1992) typology.

As far as the students of Sefrou are concerned, their classification in the category of the Honourable Egoist seems at the first glance surprising since it raises the question of the relationship between this type of socialization received and the dominant profile of the Sefroui students. The use of morality, especially the moral competence to serve one's interests is undoubtedly repressed in the cultural history of Sefrou. To account for the prevalence of the "Honorable Egoist" profile among the students of Sefrou, ethnographic description and anthropological interpretation should be highlighted. In this context, Geertz and his collaborators (1979) provided a detailed description of the dominant culture of the city by focusing on the social and economic transaction in the souk of Sefrou. Geertz has emphasized the apparent opportunism of Sefreouis through the use of nisba to get a good in a market (the souk) where the confidence is diametrically lacking and where the quality criteria are not met. In other words, to gain trust upon them, individuals, particularly, sellers characterize themselves by the attribution of names manifested in the concept of nisba (regional or familial bond ties) in their daily social interaction.

It is important to acknowledge that the process of taking advantage of the collectivist social ties and the morality of nisba used by the Sefriouis constitutes, in our opinion, the cultural framework from which the profile of the "Honorable Egoist" has evolved and developed. The use of the moral competence which is recommended by the collectivist consciousness so as to achieve one's own objectives seems, to a great extent, to be in line with the school of interpretive anthropology (Hougua, 2015).

It is crystal clear that the Virtous Advocates and the Effective Cruzaders type systems are clustered in the region of Tawjdate. It implies that the use of morality and/ or competence to contribute to the common good of the community is a common attribute of people of Tawjdate. The interpretation of this phenomenon, from an anthropological perspective, can be associated with the fact that this region is known for its cultural plurality. Indeed, different subgroups of the Amazigh and the Arabs have lived and coexisted with each other the fact that has encouraged the adoption of a tolerant attitudeand a moral obligation to anyone who does not belong to the family or cultural group. In the literature, the social dimension of the Virtuous Advocates and the Effective Crusaders typology found inTawjdate is in line with "the horizontal collectivist" cultural model (Triandis, 1995; 2001) into which individuals or groups can be classified. The prioritization of the group over the self is a fundamental attribute of the collectivist culture in its broad sense as opposed to the individualistic culture where the self, autonomy and independence from the group are more valued. The horizontal dimension of the collectivist model stresses equality as opposed to hierarchy that characterizes the vertical social construct. Thus, it is not surprising that the horizontal collectivist values including obedience, politeness, equality and social security result in the emergence of the Virtuous Advocate and the Effective Crusader models in Tawjdate.

\section{Conclusion}

The given study is the first of its type to apply the Musser and Orke (1992) value system typology to high school students in a Moroccan context. It was designed to study the value types of students with respect to two independent variables: gender and geographical area. The findings revealed no significant differences by gender in value system types. Thus, these results do not support the findings of previous research studies that confirmed gender differences in value types with males being more classified as Independent Maximizers and females were described as being Virtuous Advocates. Conversely, the results of our study affirmed that both male and female students exhibited more concern for the use of competence means to serve personal interests manifested in the widespread presence of the Independent Maximizer profile among our sample.

Interestingly, significant differences in value type preferences were observed at the level of geographical area. Indeed, the subjects surveyed in Fes fell into the category of Independent maximizers. Individuals within this classification make use of competence as an instrumental value to serve themselves. Anthropological and historical explanations embedded in the socialization process were provided to account for the prevalence of the Independent Maximizer profile among the students of Fes. The dominant value type among the students of Sefrou was that of the Honorable Egoist. People under this category are known for the use of moral means to serve personal objectives. The interpretation of this categorization was culturally associated with the social and economic transactions in the souk of sefrou where the morality of nisba was used to reach personal gain. The Virtuous Advocates and the Effective crusaders were the common attributes of students of Tawjdate. Caring for the common good by being sensitive to the needs of others was the dominant terminal value that studentsof Tawjdate prioritized. From a cultural perspective, the horizontal collectivist nature by which the dwellers of this region are characterized results in the development of the categorization of the Virtuous Advocate and the Effective Crusader with a focus on social terminal goals. 


\section{Limitations}

This study has several limitations. First of all, subjects in this study were high school students. That might have reduced the impact of gender on value type preferences. May be for future research undergraduate and post graduate university students would also be included in the sample. Second, we have to acknowledge that our findings cannot be generalised to the whole population since the study was carried out in the city of Fez and some of its suburbs. Thus, further investigations and analysis of different cultural background groups should be implemented as another direction for future research. Finally, the sample of this study is restricted to public schools; private institutions were excluded from this study because of the lack of an official administrative licence for getting access to such institutions.

Funding: This research received no external funding

Acknowledgments: Special thanks to Dr. Ahmed Aghbal (Morocco) for helping us in data processing.

Conflicts of Interest: The authors declare no conflict of interest

\section{References}

[1] Allport, G. W., Vernon, P.E. and Lindzey G.A. (1960).Study of values: A scale for measuring the dominant interests in personality. Houghton Mifflin.

[2] Arial, D.L., Abdolmohammadi, M.J. and Murphy Smith, L. (2012). Ethical predisposition of certified public accountants: A study of gender differences. Research on professional responsibility and ethics in accounting, 16, 29-56.

[3] Banfield, E. C. (1958). The moral basis of a backward society. New York: Free Press.

[4] Chraïbi, D. (1954). Le passé simple. Paris. Denoël : coll. Folio n 1728.

[5] Eaton,T .V. and Giacomino, D.E. (2000). Personal values of business students: Differences by gender and discipline.Research on accounting ethics, 7, 83-102.

[6] Eaton,T .V. and Giacomino, D.E. (2001). An examination of personal values: Differences between accounting students and managers and differences between genders. Teaching business ethics, 5, 213-229.

[7] Feather, N. T. (1985).Values in education and society. New York: Free Press.

[8] Gellermann, W., Frankel, M.,and Ladenson, R.(1990). Values and ethics in organization and human systems development: Responding to dilemmas in professional life. CA: Jossey-Bass.

[9] Giacomino, D.E., Fujita, A., and Johnson, T.M. (1999) Are the Effects of Age and Gender Changing the Personal Values of Japanese Executives?' Business Forum. 24(1/2),15-21.

[10] Giacomino, D. E., \& Eaton, T. V. (2003). Personal values of accounting alumni: An empirical examination of differences by gender and age.Journal of Managerial Issues, 15(3), 369-380.

[11] Giacomino, D. E., Li,X., \& M. D. Akers. (2013). An examination of personal values and value systems of Chinese and U.S. business students.American Journal of BusinessEducation, 6(1), 119-128.

[12] Geertz, C. (1979). Suq: The bazaar economy in Sefrou'. In L. Rosen et al. (Eds.).Meaning and order in contemporary Morocco: Three essays in cultural analysis. NewYork:Forthcoming.

[13] Hougua, B. A. (2016). Les dimensions verticales et horizontales de l'individualisme et du collectivisme dans le context culturel marocain. Les Cahiers Psychologie Politique. [En ligne], numéro 27, Juillet 2015. URL :

http://lodel.irevues.inist.fr/cahierspsychologiepolitique/index.php?id=3065

[14] Hougua, B. A. (2018). Culture politique et action protestataire au Maroc: Incidences desfacteurs culturels sur la disposition à la protestation chez les Marocains. Unpublished Ph. D. Thesis. Rabat: University Mohamed V.

[15] Hougua, B. (2019). Amoral familism and the future of democracy in the Arab World: Geneology of familism syndrome and its political effects. In Arabic, Loubal, AljazeraCenter for Studies, pp. 9-40.

[16] Hultman, K. E. (2017). Unleashing the power of values.Organization Development Journal, 35(2), 17-32

[17] Kluckhohn, C. (1951). Values and value orientations in the theory of action: An exploration in definition and classification.' In T. Parsons \& E. Shils (Eds.), Toward a General Theory of Action (pp. 388-433). Cambridge, MA: Harvard University Press.

[18] Lee, J. A., Soutar, G., \& Louviere, J. (2008). The Best-worst scaling approach: An

[19] alternative to Schwartz's values survey. Journal of Personality Assessment,90(4), 335-347. doi: 10.1080/00223890802107925

[20] Lotti, P. (1890). Au Maroc. Casablanca, Eddif, 2008.

[21] Mayton, D. M., Ball-Rokeach, S. J., and Loges, W. E. (1994). Human values and social issues: An introduction.Journal of Social Issues, 50(4), 9-18.

[22] Musser, S. J., and Orke, E.A..(1992). Ethical value systems: A typology. The Journal

[23] of Applied Behavioral Science, 28(3), 348-362.

[24] Rokeach, M. (1973). The nature of human values. New York: Free Press.

[25] Schwartz, S. H. (1992). 'Universals in the Content and Structure of Values: Theoretical Advances and Empirical Tests in 20 Countries.' In M. Zanna (Ed.) Advances in Experimental Social Psychology, 25, 1-65. New York: Academic Press.

[26] Schwartz, S. H. (2012). An overview of the Schwartz theory of basic values.Online Readings in Psychology and Culture, 2(1), 1-20.

[27] Smith, P. B., \& Schwartz, S. H. (1997).Values.In J. W. Berry, M. H. Segall\& C.

[28] Kagitcibasi (Eds.), Handbook of cross-cultural psychology, 3, 77-118. Boston, MA: Allyn\& Bacon

[29] Triandis, H. C. (1995). Individualism and collectivism. Boulder, CO: Westview Press. 
[30] Triandis, H. C. (2001). Individualism-collectivism and personality.Journal of Personality, 69(6), 907-924.

[31] Tuulik, K., Õunapuu, T., Kuimet, K., andTitov, E. (2016). Rokeach's instrumental and terminal values as descriptors of modern organisation values.International Journal of Organizational Leadership, 5, 151-161

[32] Waterbury, J. (1970). The Commander of the faithful. The Moroccan political elite: A study in segmented politics. London: Weidenfeld and Nicolson.

[33] Williams, R. M. (1968). The concept of values.In D. L. Sills (Ed.), International encyclopaedia of the social sciences (pp.283-287). New York: Macmillan. 